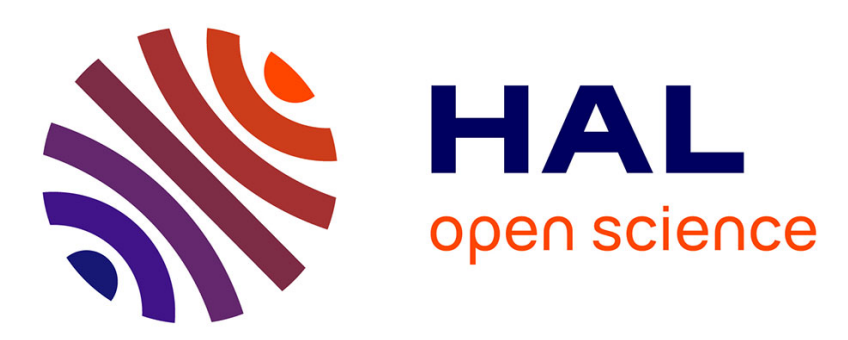

\title{
Finite Element Modeling of Cell Exposed To Harmonic and Transient Electric Fields
}

\author{
Ivan Meny, Noël Burais, François Buret, Laurent Nicolas
}

\section{To cite this version:}

Ivan Meny, Noël Burais, François Buret, Laurent Nicolas. Finite Element Modeling of Cell Exposed To Harmonic and Transient Electric Fields. IEEE Transactions on Magnetics, 2007, 43 (4), pp.1773-1776. 10.1109/TMAG.2007.892517 . hal-00136656v2

\section{HAL Id: hal-00136656 https://hal.science/hal-00136656v2}

Submitted on 10 Apr 2007

HAL is a multi-disciplinary open access archive for the deposit and dissemination of scientific research documents, whether they are published or not. The documents may come from teaching and research institutions in France or abroad, or from public or private research centers.
L'archive ouverte pluridisciplinaire HAL, est destinée au dépôt et à la diffusion de documents scientifiques de niveau recherche, publiés ou non, émanant des établissements d'enseignement et de recherche français ou étrangers, des laboratoires publics ou privés. 


\title{
Finite-Element Modeling of Cell Exposed to Harmonic and Transient Electric Fields
}

\author{
I. Meny ${ }^{1}$, N. Burais ${ }^{2}$, F. Buret ${ }^{1}$, and L. Nicolas ${ }^{1}$ \\ ${ }^{1}$ Centre de Genie Electrique de Lyon (CEGELY), Ecole Centrale de Lyon, 69134 Ecully, France \\ ${ }^{2}$ Centre de Genie Electrique de Lyon (CEGELY), Université Claude Bernard Lyon 1, 69622 Villeurbanne, France
}

\begin{abstract}
The transmembrane potential (TMP) of a cell exposed to harmonic or transient electric fields is the main parameter for a successful permeabilization of a cell. Obviously, TMP can be computed with a finite-element method, but the high contrast between sizes and electromagnetic properties of the cytoplasm, the membrane, and the extra-cellular medium leads sometimes to inaccurate numerical results. Influences of membrane conductivity and frequency on the accuracy are studied. Optimization of transient waveforms is proposed for various shapes of cells.
\end{abstract}

Index Terms-Bioelectric phenomena, biological cells, electromagnetic field computing, finite-element method (FEM).

\section{INTRODUCTION}

$\mathbf{E}$ LECTROPERMEABILIZATION is an effective method for achieving transmembrane transport of molecules which otherwise cannot cross cell membrane; it can be used, in particular, for gene transfection and electrochemical therapy [1]. Theory and experiments have shown that the extent of permeabilization depends on cell size [2], shape, orientation [3], [4], and interaction with surrounding cells [5]. However, the efficiency of electropermeabilization depends, above all, on effective tissue conductivity and on the parameters of applied electric pulses. Investigations of the role of the amplitude, number, duration, and shape of these pulses have been the subject of several experimental studies [6]-[9]. However, the role of pulse shape in electroporation has not yet been studied with a transient modeling at the cell level.

The induced transmembrane potential (TMP), which causes permeabilization, depends on the local electric field and not on the average applied field usually reported in experimental studies or predicted by tissue-level simulations. For spheroidal cells, the potential distribution can be obtained through analytical solutions of Laplace's equation [4], [10], [11]. These analytic solutions have yet limited use in estimating TMP, as they can be obtained only for very simple shapes of cells. The application of numerical methods to cell problems provides the ability to model more complex and more actual geometries. Nevertheless, the very small thickness of the cell membrane and the high contrast between material properties make it difficult to obtain an accurate numerical modeling. The finite-element method (FEM) is well suited to model the geometry of actual cells and also permits the membrane to be modeled in detail without increasing the resolution over the entire problem space. Therefore, this method has been used in order to get an accurate

Digital Object Identifier 10.1109/TMAG.2007.892517

Color versions of one or more of the figures in this paper are available online at http://ieeexplore.ieee.org.

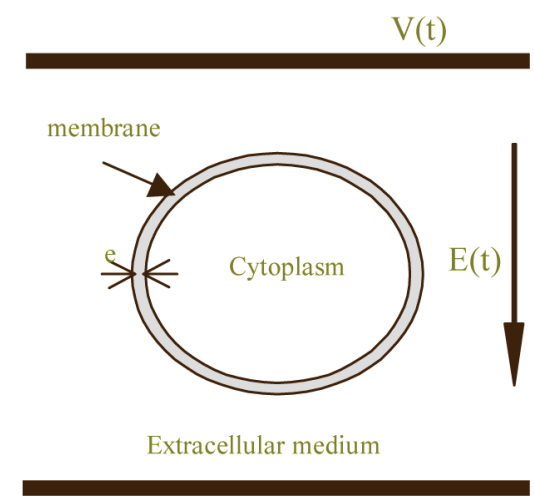

Fig. 1. Typical simulated cell problem.

insight of the electric field distribution inside cells with complex geometries [3], [12], [13], to make studies at the tissue scale [14], [15], or transient analyses with a wide variety of applied voltage waveforms [16].

In this paper, FEM is used to calculate the TMP in a single cell exposed to harmonic or transient electric fields induced by a voltage applied between two parallel plane electrodes. The influence of the membrane conductivity and the frequency on the accuracy is investigated. It must be noticed that most of the time this aspect is not taken into account by the authors who use commercial FEM packages. Next, the waveform of applied pulses is optimized by investigating the effects of the signal rising rate. The validity range of the analytical expressions is evaluated with FEM calculations. Finally, the slew-rate specifications recommended for the signal generators used in experiments are deduced.

\section{Electromagnetic Model of a Single Cell}

The studied structure (Fig. 1) is a single (spherical or elliptical) cell exposed to harmonic or transient electric fields induced by a voltage applied between two electrodes. TMP is calculated by solving the electro-quasi-static equation which is formulated under complex form for time-sinusoidal electric field

$$
(\sigma+j \varepsilon \omega) \Delta \underline{V}=0
$$


TABLE I

EleCtric AND Size Parameters of a SPHERICAl CELl

\begin{tabular}{ll}
\hline Parameters & Denotation and value \\
\hline Cytoplasmic conductivity & $\sigma_{\mathrm{i}}=0.53 \mathrm{~S} / \mathrm{m}$ \\
Cytoplasmic permittivity & $\varepsilon_{\mathrm{i}}=4.42 \times 10^{-10} \mathrm{As} / \mathrm{Vm}$ \\
Membrane conductivity & $\sigma_{\mathrm{m}}=5 \times 10^{-7} \mathrm{~S} / \mathrm{m}$ \\
Membrane permittivity & $\varepsilon_{\mathrm{m}}=7.96 \times 10^{-11} \mathrm{As} / \mathrm{Vm}$ \\
Extracellular medium & $\sigma_{\mathrm{o}}=10^{-2} \mathrm{~S} / \mathrm{m}$ (low-conductivity \\
conductivity & medium) \\
& $\sigma_{\mathrm{o}}=0.12 \mathrm{~S} / \mathrm{m}$ (physiological medium) \\
& $\sigma_{\mathrm{o}}=1.2 \mathrm{~S} / \mathrm{m}$ (blood serum) \\
Cell radius & $\mathrm{R}=10 \mu \mathrm{m}$ (eukaryote cell) \\
& $\mathrm{R}=1 \mu \mathrm{m}$ (prokaryote cell) \\
Membrane thickness & $\mathrm{e}=5 \mathrm{~nm}$ \\
Distance between electrodes & $\mathrm{d}=50 \mu \mathrm{m}$ \\
\hline
\end{tabular}

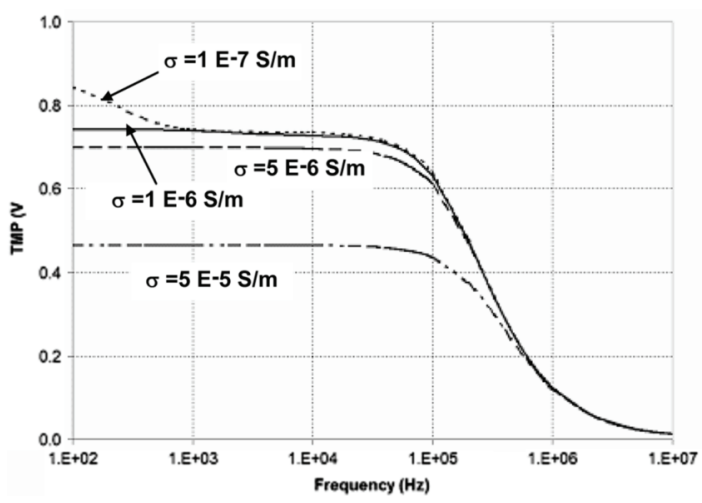

Fig. 2. Frequential variations of TMP for various conductivities of membrane.

or a time step form for transient field (implicit scheme)

$$
(\sigma+\varepsilon / d t) \Delta V^{(t)}=(\varepsilon / d t) \Delta V^{(t-d t)}
$$

where $\varepsilon=\varepsilon_{0} \cdot \varepsilon_{r}$, and $d t$ the time step.

Equations (1) and (2) are solved by 3-D axisymmetrical FEM.

Typical electric and size parameters of cytoplasm, membrane, and extracellular medium are defined in Table I for a spherical cell.

\section{HARMONIC SIMULATION}

Because of the great difference between cell size and membrane thickness $(\approx 1 / 2000)$, particular attention must be paid to the FEM mesh structure.

For very low conductivities of the membrane compared with cytoplasmic and extracellular conductivities, TMP curve can exhibit anomalies in harmonic simulation (Fig. 2). This "phenomena" appears only for frequencies below $1 \mathrm{kHz}$ and does not influence the results for frequencies range used classically in the electropermeabilization process.

\section{Transient Simulation Study}

The parametric study is performed in order to investigate the influence of the slope $d V / d t$ of the applied signal on the permeabilization efficiency. The TMP threshold voltage $V_{s}$ which allows to obtain a reversible permeabilization is ranging from 0.25 to $1 \mathrm{~V}$, depending on the type of cell. For example, a rather precise estimate gives $V_{s}$ equal to $0.5 \mathrm{~V}$ for hepatocytes [15]. In this study, the threshold value is set to $0.4 \mathrm{~V}$. The signal applied between the electrodes is a step turn-on, with a rising time greater than the time $t_{s}$ required to reach $V_{s}$. In this way, the only relevant parameter for the applied signal is the slope $d V / d t$.

\section{A. Analytical and FEM Study of TMP for Spherical Cell}

The classical theory of TMP developed by Schwan [17] leads to a temporal description of this phenomenon as a first-order process. The expression of the TMP $V_{m}$ as a function of the time during the rising edge of the signal is

$$
V_{m}(t)=K \frac{d V}{d t}\left(t-\tau+\tau e^{-\frac{t}{\tau}}\right)
$$

by assuming that TMP is measured along the cell axis.

The dc gain $K$ can be calculated by using the approximate expression of the TMP

$$
V_{m}=\frac{3}{2} E R \quad E=\frac{V_{\text {app }}}{d} \quad K=\frac{3 \cdot R}{2 \cdot d}
$$

where $E$ is the strength of the electric field and $V_{\text {app }}$ is the applied voltage between the two electrodes.

A more accurate analytical expression of the TMP [11] leads to the following equation:

$$
\begin{aligned}
& K=3 e \sigma_{o}\left(\sigma_{i}\left(3 R^{2}-3 e R+e^{2}\right)+\sigma_{m}\left(3 e R-e^{2}\right)\right) \\
& \frac{2 R^{3}\left(\sigma_{m}+2 \sigma_{o}\right)\left(\sigma_{m}+\frac{1}{2} \sigma_{i}\right)+2(R-e)^{3}\left(\sigma_{m}-\sigma_{o}\right)\left(\sigma_{i}-\sigma_{m}\right)}{\times \frac{R}{d}} .
\end{aligned}
$$

With the numerical values given in Table $\mathrm{I}$, by taking $R=$ $10 \mu \mathrm{m}$ and $\sigma_{o}=0.12 \mathrm{~S} / \mathrm{m}$, we find $K=0.3$ with (4) and $K=0.298$ with (5). As the difference between these two results is very low, (4) will be used for analytical calculations.

The time constant $\tau$ of the membrane is given [18] by

$$
\tau=\frac{R \frac{\varepsilon_{m}}{e}}{\frac{2 \sigma_{o} \sigma_{i}}{2 \sigma_{o}+\sigma_{i}}+\frac{R}{e} \sigma_{m}} .
$$

TMP values are calculated with FEM and with (3) by taking $R=10 \mu \mathrm{m}, \sigma_{o}=0.12 \mathrm{~S} / \mathrm{m}$ and $d V / d t=6 \mathrm{~V} / \mu \mathrm{s}$. Equivalent results are obtained. So, the first-order theory seems to be valid during the rising phase of the signal.

In order to investigate the influence of the slope $d V / d t$, we focus on the time $t_{s}$ required to reach $V_{s}$. Experiments show that the time during which the amplitude of the applied pulse exceeds a certain critical value, has a major role in the efficiency of electropermeabilization [6]. It is assumed here that this critical value is linked with the reversible threshold $V_{s}$ of permeabilization.

An analytical expression of $t_{s}$ needs the reciprocal of the function $V_{m}(t)$ written in (3) to be determined. As $V_{m}^{-1}$ cannot be directly calculated, (3) is simplified by noticing that $t_{s}$ is much greater than $\tau$ in most of the cases, especially for the lowest values of $d V / d t$ : in Table II, we show some values of $t_{s}$ obtained with $R=10 \mu \mathrm{m}$ and $\sigma_{o}=0.12 \mathrm{~S} / \mathrm{m}$, i.e., $\tau=0.96 \mu \mathrm{s}$.

The exponential term in (3) may be neglected, and an expression of $t_{s}$ as a function of $V_{s}$ and $d V / d t$ would be

$$
t_{s}=\frac{V_{s}}{K \frac{d V}{d t}}+\tau \text {. }
$$


TABLE II

VALUES OF $t_{s}$ FOR $\tau=0.96 \mu \mathrm{s}$

\begin{tabular}{cc}
\hline $\mathrm{dV} / \mathrm{dt}(\mathrm{V} / \mu \mathrm{s})$ & $\mathrm{t}_{\mathrm{s}}(\mu \mathrm{s})$ \\
\hline 6 & 0,73 \\
3 & 1,1 \\
1 & 2,2 \\
0,5 & 3,6 \\
0,2 & 7,7 \\
0,06 & 23,6 \\
0,03 & 46 \\
0,01 & 138 \\
\hline
\end{tabular}
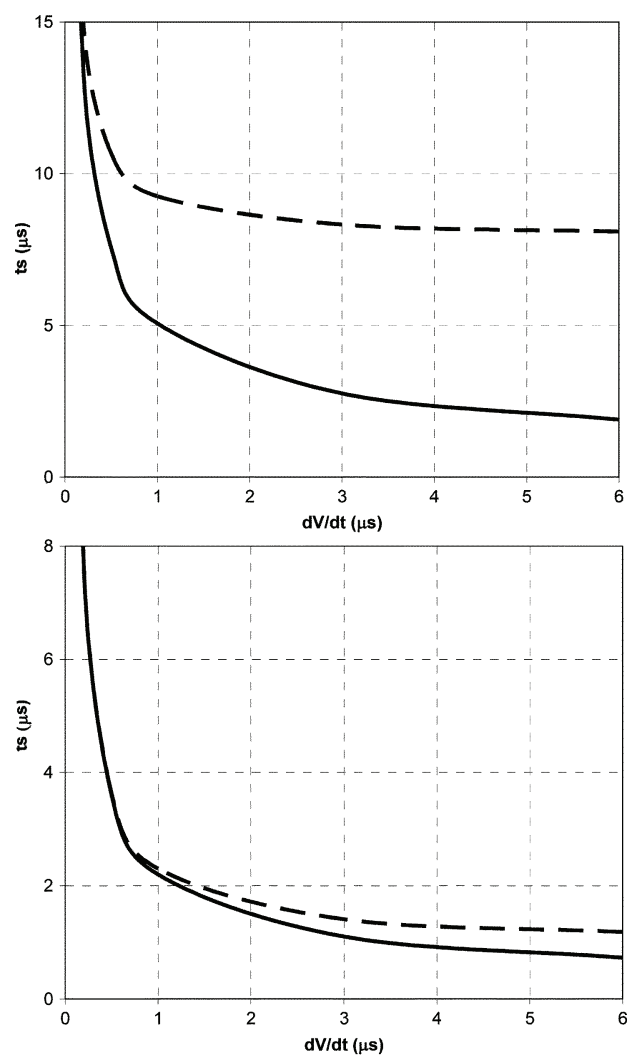

Fig. 3. $t_{s}$ versus $d V / d t$ : FEM values (solid curve) and analytical values obtained from (7) (dashed curve): $R=10 \mu \mathrm{m}, \sigma_{o}=10^{-2} \mathrm{~S} / \mathrm{m}$ (up) $\sigma_{o}=0.12$ $\mathrm{S} / \mathrm{m}($ down)

In Fig. 3, values of $t_{s}$ given by FEM calculations are compared with analytical values given by (7) for $R=10 \mu \mathrm{m}$ (order of magnitude of eukaryote cells sizes). Others calculations are performed for $R=1 \mu \mathrm{m}$ (prokaryote cells), but the FEM and analytical curves are quite similar. Different values of $\tau$ are obtained by varying the extracellular medium conductivity: for $R=1 \mu \mathrm{m}$ and $R=10 \mu \mathrm{m}, \tau$ is, respectively, equal to: $0.82 \mu \mathrm{s}$ and $7.9 \mu \mathrm{s}$ for $\sigma_{o}=10^{-2} \mathrm{~S} / \mathrm{m}, 0.096 \mu \mathrm{s}$, and $0.96 \mu \mathrm{s}$ for $\sigma_{o}=$ $0.12 \mathrm{~S} / \mathrm{m}, 0.037 \mu \mathrm{s}$, and $0.37 \mu \mathrm{s}$ for $\sigma_{o}=1.2 \mathrm{~S} / \mathrm{m}$.

The accuracy of the analytical expression of $t_{s}$ improves when the slope $d V / d t$ and $\tau$ present low values. For $R=10 \mu \mathrm{m}$, it can be noticed that for a given value of $d V / d t$, values of $\mathrm{t}_{\mathrm{s}}$ change with $\sigma_{o}$, when $t_{s}$ remains almost unchanged whatever $\sigma_{o}$ may be. When the distance between electrodes is in the same order of magnitude as the cell radius (e.g., $R=10 \mu \mathrm{m}$ and $d=50 \mu \mathrm{m}$ ), $t_{s}$ is influenced by the cytoplasm and the extracellular medium conductivities: $\tau$ is not

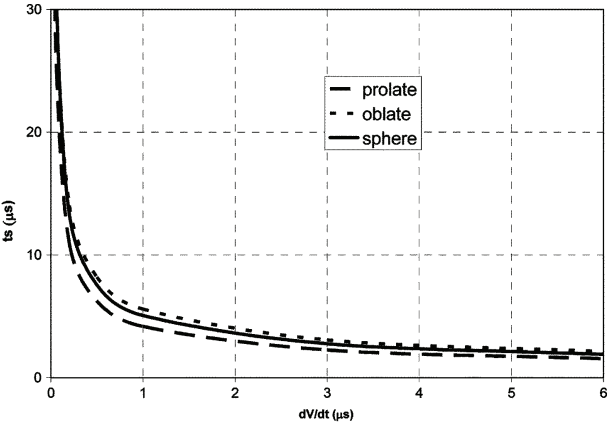

Fig. 4. Time $t_{s}$ versus $d V / d t$ for spherical and elliptic cells $\left(\sigma_{0}=10^{-2} \mathrm{~S} / \mathrm{m}\right)$.

negligible in (7) and becomes even predominant for high values of $d V / d t$. On the other hand, when $R$ is much smaller than $d$ (e.g., $R=1 \mu \mathrm{m}$ and $d=50 \mu \mathrm{m}$ ), $t_{s}$ depends first of all on applied signal. So, the spherical-cell model makes it possible to establish analytical relations, from which we deduced (7).

\section{B. FEM Study of TMP for Elliptical Cell}

By using FEM, the TMP evolution for elliptic cells can be calculated, this shape being closer to reality. Fig. 4 shows values of $t_{s}$ obtained with prolate ("cigar-shaped"), oblate ("disk-shaped"), and spherical cells.

For the spherical cell: $R=10 \mu \mathrm{m}$, for the prolate cell: $R_{1}=$ $15 \mu \mathrm{m}$ and $R_{2}=10 \mu \mathrm{m}$, for the oblate cell: $R_{1}=10 \mu \mathrm{m}$ and $R_{2}=15 \mu \mathrm{m}, R_{1}$ and $R_{2}$ being, respectively, the radius along the axis of rotational symmetry and the radius perpendicular to this axis.

The evolution of $t_{s}$ is the same with the three cell shapes: we can distinguish a sharp decrease and a very slow decrease area, the transition between these two zones takes place for the same values of $d V / d t$. The two areas can be delimited with the curve point where the derivative is equal to -1 . By taking the spherical-cell as a reference and using (7), we find that this value of the derivative occurs for

$$
\left(\frac{d V}{d t}\right)_{l}=\sqrt{\frac{V_{s}}{K}}
$$

\section{Optimization of the Applied Signal}

Pulses used for electropermeabilization can be very short, especially for eukaryote cells, on which single rectangular pulses of $100-\mu$ s duration are often applied.

On the one hand, it seems necessary in this case to use pulse generators able to deliver signals with slopes greater than $(d V / d t)_{l}$, otherwise the TMP would remain below the reversible threshold during a time $t_{s}$ which is not negligible in comparison with the total pulse duration. Moreover, this time $t_{s}$ would not be precisely controlled: it depends particularly on the gain $K$ and the threshold value $V_{s}$, which are generally imprecisely known and present heterogeneous values. Then, for low values of $d V / d t, t_{s}$ could be very different from a cell to another; the effective duration of the applied pulses being unknown, the experiments would not be fully repeatable. On the other hand, generator pulses with slew-rates much greater than $(d V / d t)_{1}$ seem unnecessary, at least for high values of 


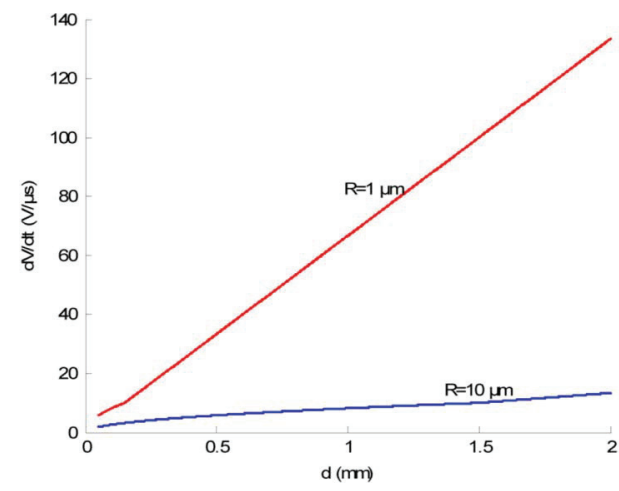

Fig. 5. $(d V / d t)_{m}$ versus distance between electrodes.

$K$ : the gain achieved on $t_{s}$ with very high $d V / d t$ is minor in comparison with the total pulse duration.

The threshold $V_{s}$ being estimated less than $1 \mathrm{~V},(8)$ is upperbounded by

$$
\left(\frac{d V}{d t}\right)_{m}=\sqrt{\frac{1}{K}}=\sqrt{\frac{2 d}{3 R}} .
$$

This value would then be the minimum acceptable slope for the applied signal. However, the distance between electrodes is often in the order of one millimeter in experiments. Low values of $K$ can then be reached and $t_{s}$ becomes significant in comparison with the total pulse duration, even if $d V / d t$ is greater than $(d V / d t)_{m}$. Considering a pulse of $100 \mu$ s duration, if we want $t_{s}$ to remain less than $10 \mu \mathrm{s}$, for example, the minimum slope for $K<0.01$ has to be

$$
\left(\frac{d V}{d t}\right)_{m_{K<0.01}}(V / \mu s)=\frac{(0.1)}{K}=\frac{(0.2) d}{3 R} .
$$

Fig. 5 shows values of $(d V / d t)_{m}$ in case of spherical cells with a radius $R=1 \mu \mathrm{m}$ and $R=10 \mu \mathrm{m}$, for a distance $d$ between electrodes included in [ $50 \mu \mathrm{m} ; 2 \mathrm{~mm}$ ]. It can be seen that high values of slew-rate can be required for $R=1 \mu \mathrm{m}$. In this case, special generators or reduction of the distance between electrodes may be necessary.

\section{CONCLUSION}

Electro-quasi-static formulation and FEM resolution can be used to calculate harmonic and transient TMP, but because of the very low thickness of membrane, particular attention must be paid to the mesh structure. FEM and analytical calculations of TMP has been performed for spherical cells in order to obtain optimization parameters of signal (threshold time $t_{s}$ and slope $d V / d t$ ). For elliptical cells, FEM studies show that the results are similar, and the same analytical expressions can also be used to optimize the applied signal. Next, works will be devoted to FEM study of inhomogenous cytoplasm in cell, to membrane modeling by "shell element" and optimization of other waveforms.

\section{REFERENCES}

[1] K. H. Schoenbach, S. Katsuki, R. H. Stark, E. S. Buescher, and S. J. Beebe, "Bioelectrics-new applications for pulsed power technology," IEEE Trans. Plasma Sci., vol. 30, no. 1, pp. 293-300, Feb. 2002.

[2] S. Hojo, K. Shimizu, H. Yositake, M. Muraji, H. Tsujimoto, and W. Tatebe, "The relationship between electropermeabilization and cell cycle and cell size of Saccharomyces Cerevisiae," IEEE Trans. Nanobiosci., vol. 2, no. 1, pp. 35-39, Mar. 2003.

[3] B. Valic, M. Golzio, M. Pavlin, A. Schatz, C. Faurie, B. Gabriel, J. Tessié, M. P. Rols, and D. Miklavcic, "Effect of electric field induced transmembrane potential on spheroidal cells: Theory and experiment,' Eur. Biophys. J., vol. 32, pp. 519-528, Sep. 2003.

[4] J. Gimsa and D. Wachner, "Analytical description of the transmembrane voltage induced on arbitrarily oriented ellipsoidal and cylindrical cells," Biophys. J., vol. 81, pp. 1888-1896, Oct. 2001.

[5] T. R. Gowrishankar and J. C. Weaver, "An approach to electrical modeling of single and multiple cells," PNAS, vol. 100, p. 3203, Mar. 2003.

[6] T. Kotnik, G. Pucihar, M. Rebersek, D. Miklavcic, and L. M. Mir, "Role of pulse shape in cell membrane electropermeabilization," Biochimica et Biophysica Acta, no. 1614, pp. 193-200, Aug. 2003.

[7] M. P. Rols and J. Tessié, "Electropermeabilization of mammalian cells to macromolecules: Control by pulse duration," Biophys. J., vol. 75, p. 1415, Sep. 1998.

[8] N. Eynard, F. Rodriguez, J. Trotard, and J. Teissié, "Electrooptics studies of escherichia coli electropulsation: Orientation, permeabilization, and gene transfer," Biophys. J., vol. 75, pp. 2587-2596, Nov. 1998.

[9] R. P. Joshi, Q. Hu, and K. H. Schoenbach, "Dynamical modeling of cellular response to short-duration, high-intensity electric fields," IEEE Trans. Dielectr. Electr. Insul., vol. 10, no. 5, pp. 778-787, Oct. 2003.

[10] T. Kotnik, F. Bobanovic, and D. Miklavcic, "Sensitivity of transmembrane voltage induced by applied electric fields-A theoretical analysis," Bioelectrochem. Bioenergetics, no. 43, p. 285, 1997.

[11] T. Kotnik, D. Miklavcic, and T. Slivnik, "Time course of transmembrane voltage induced by time-varying electric fields-A method for theoretical analysis and its application," Bioelectrochem. Bioenergetics, no. 45, pp. 3-16, 1998.

[12] E. C. Fear and M. A. Stuchly, "Modeling assemblies of biological cells exposed to electric fields," IEEE Trans. Biomed. Eng., vol. 45, no. 10, pp. 1259-1271, Oct. 1998.

[13] C. E. Miller and C. S. Henriquez, "Three-dimensional finite element solution for biopotentials: Erythrocyte in an applied field," IEEE Trans. Biomed. Eng., vol. 35, no. 9, pp. 712-718, Sep. 1988.

[14] D. Miklavcic, D. Semrov, H. Mekid, and L. M. Mir, "A validated model of in vivo electric field distribution in tissues for electrochemetherapy and for DNA electrotransfer for gene therapy," Biochimica et Biophysica Acta, no. 1523, pp. 73-83, Sep. 2000.

[15] D. Sel, D. Cukjati, D. Batiuskaite, T. Slivnik, L. M. Mir, and D Miklavcic, "Sequential finite element model of tissue electropermeabilization," IEEE Trans. Biomed. Eng., vol. 52, no. 5, pp. 816-827, May 2005.

[16] S. H. Jayaram and S. A. Boggs, "Optimization of electroporation waveforms for cell sterilization," IEEE Trans. Ind. Appl., vol. 40, no. 6, pp. 1489-1497, Nov./Dec. 2004.

[17] H. P. Schwan, "Electrical properties in tissue and cell suspensions," Adv. Biol. Med. Phys., vol. 5, pp. 147-209, 1957.

[18] H. Pauly and H. P. Schwan, "Impedance of a suspension of ball-shaped particles with a shell," Z. Naturforsch, vol. 14B, pp. 125-131, Feb. 1959.

Manuscript received April 21, 2006 (e-mail: burais@ cegely.univ-lyon1.fr). 